\title{
Counseling Guideline
}

\author{
Genetic counseling for \\ hereditary breast and ovarian \\ cancer
}




\section{Motivation}

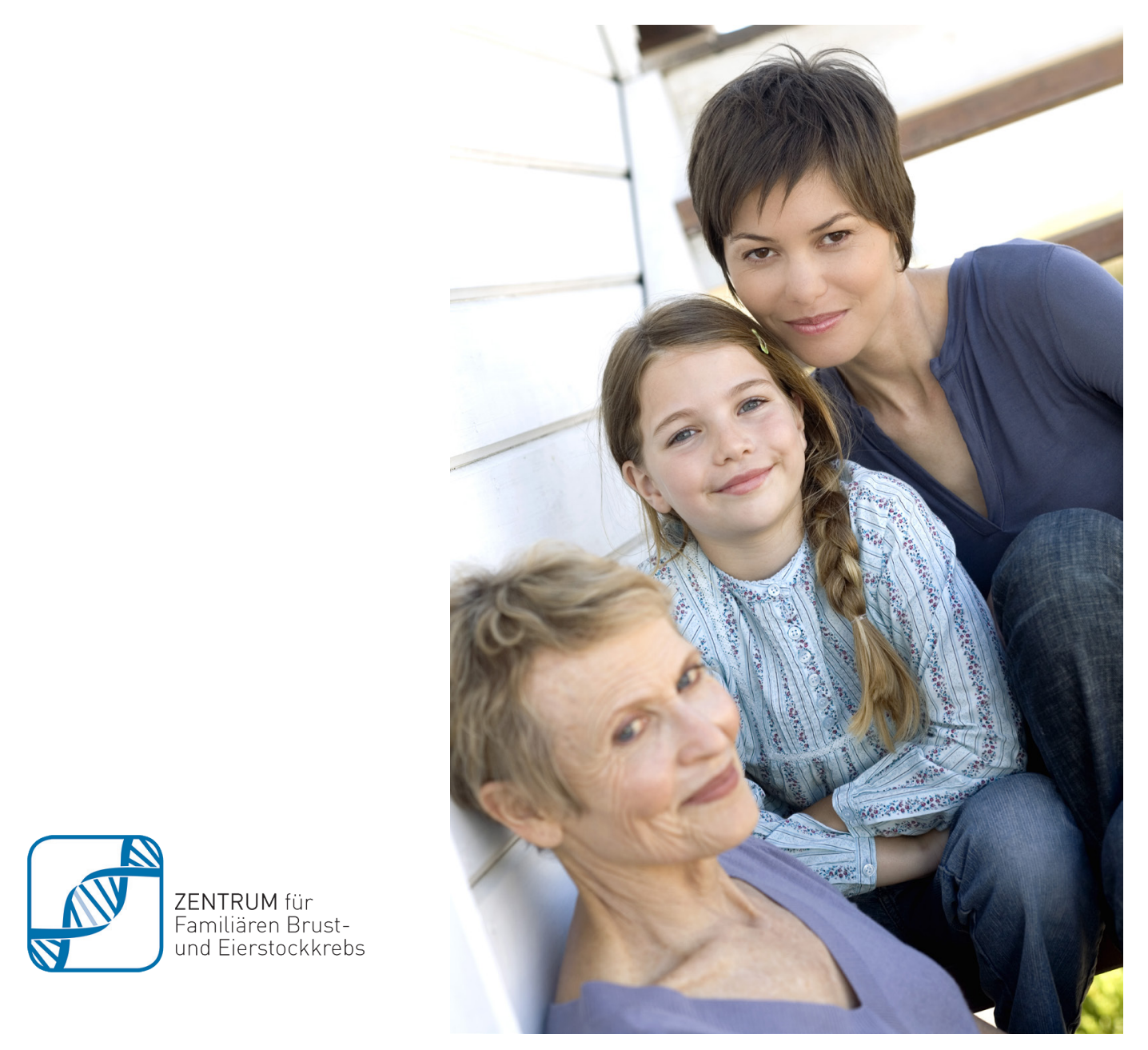

What brings you to genetic counseling today? 


\section{Stages of consultation}

1. Genetic background

2. Family pedigree creation

3. Decision-making

- medical indication

- personal decision

- possible consequences 


\section{Breast and Ovarian Cancer}

- One in eight women will develop breast cancer over the course of her lifetime (lifetime risk: 12.5\%)

- One out of every 70 woman will develop ovarian cancer at some point in her lifetime (lifetime risk: 1-2\%)

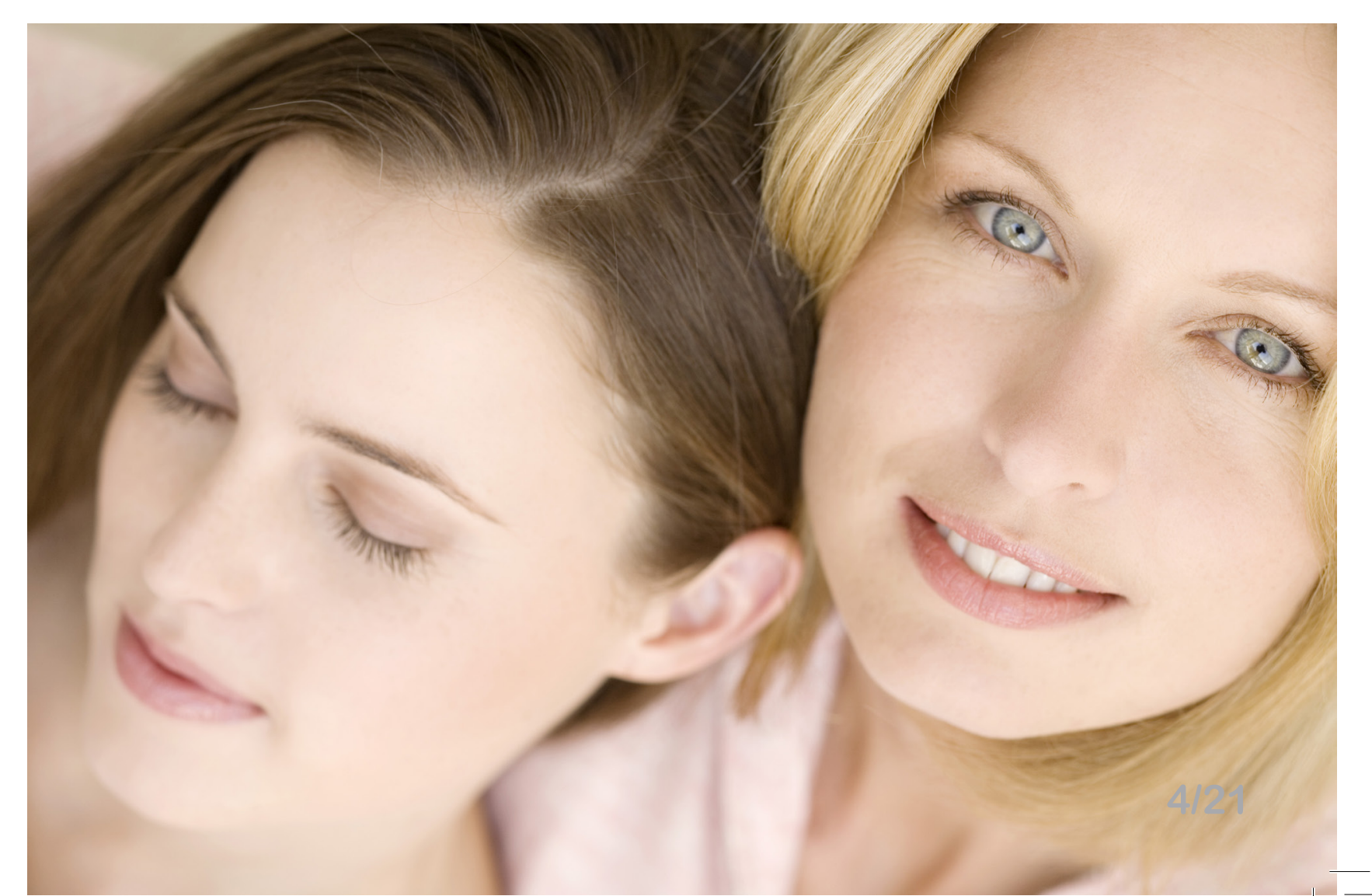




\section{Genetic Background}

- The complete genetic blueprint for your body is found in the nucleus of each cell in the form of DNA

- DNA = deoxyribonucleic acid (deoxyribonucleic acid)

- Gene: Sections of the DNA that determine features of the human body, e.g. blood type, eye color

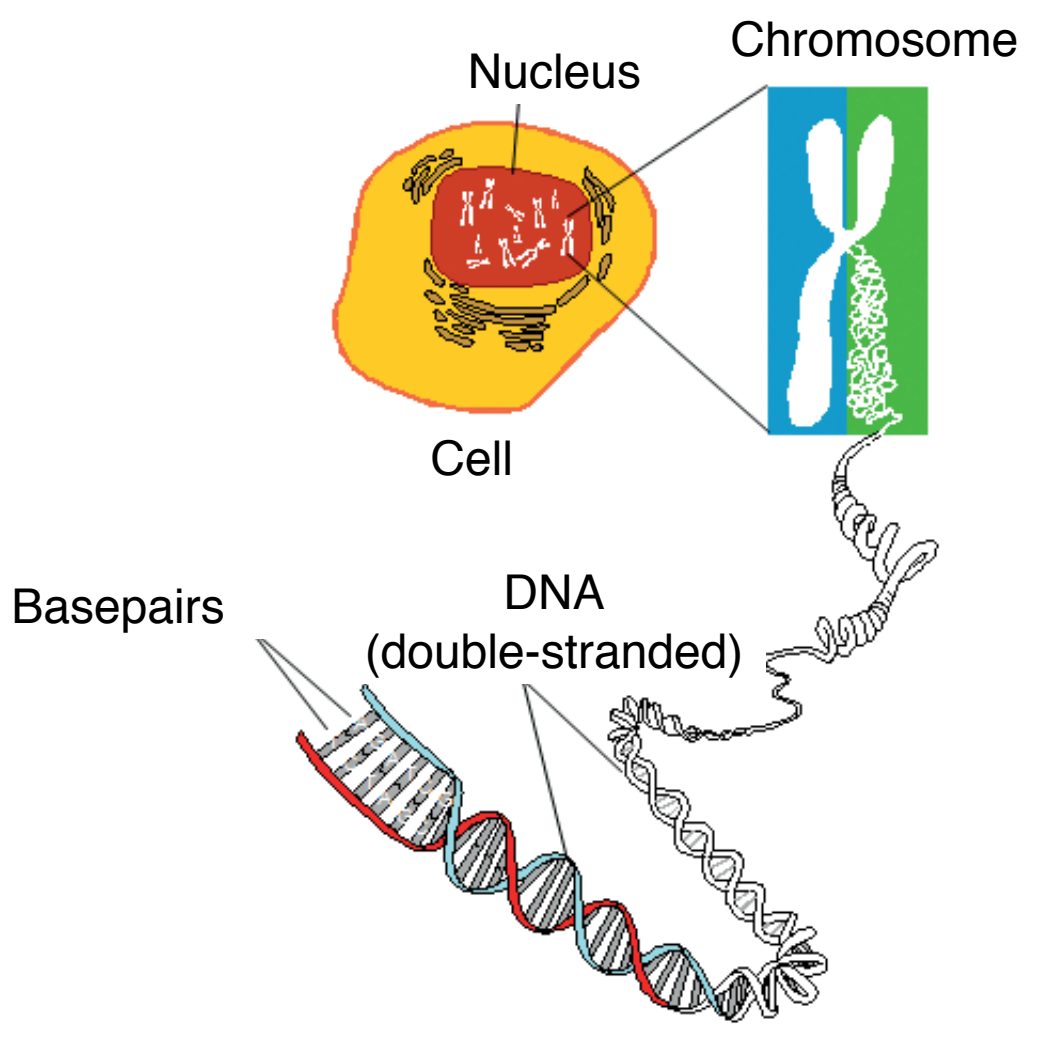




\section{$B R C A 1$ and $B R C A 2$}

Since 1994 (BRCA1) and 1995 (BRCA2) were discovered

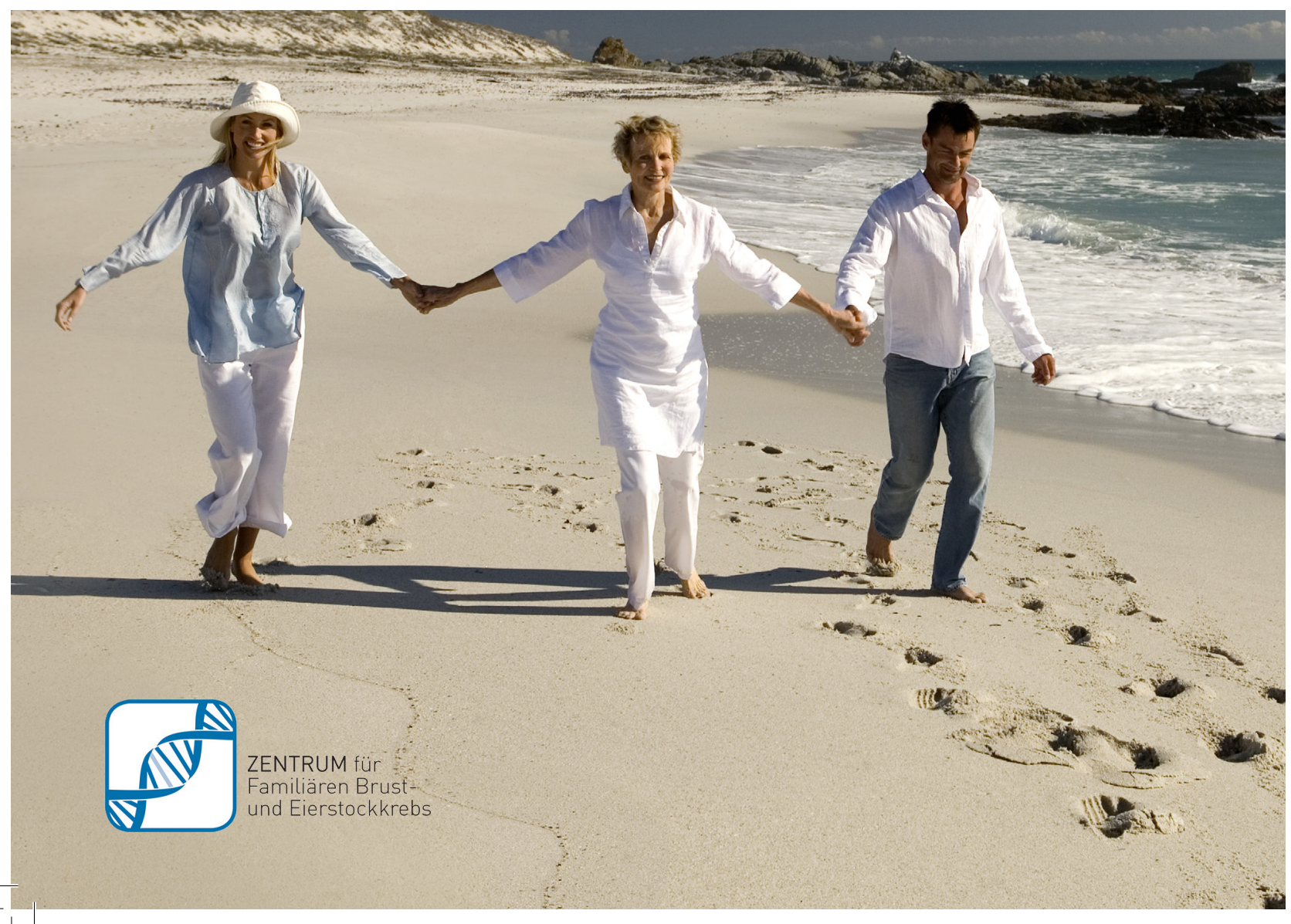

BRCA1 $=$ BReast CAncer 1

BRCA2 = BReast CAncer 2

- Repair genes

(Tumor suppressor genes)

- They are very important to avoid cancer

- Everyone has it (women and men!) 


\section{$B R C A 1$ and $B R C A 2$}

What happens with a change (= mutation) in one of these genes?

- Gene modification is innate

- Impaired repair function

- Strong risk increase for breast and ovarian cancer (and low risk of other cancers)

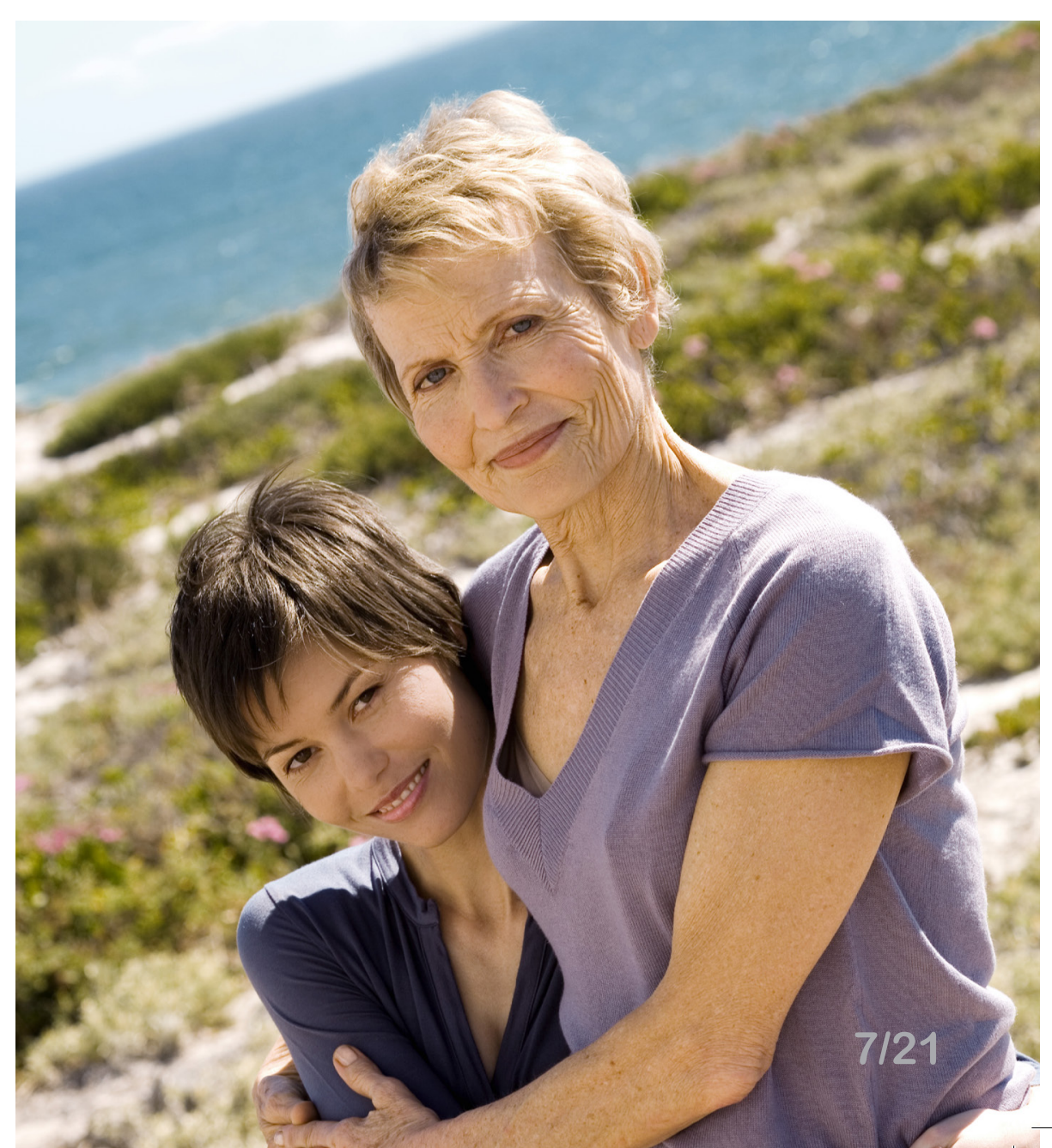




\section{Genetic breast cancer}

- $90-95 \%$ sporadic breast cancer

- $5-10 \%$ of all breast cancers are inherited, the causes are genetic changes

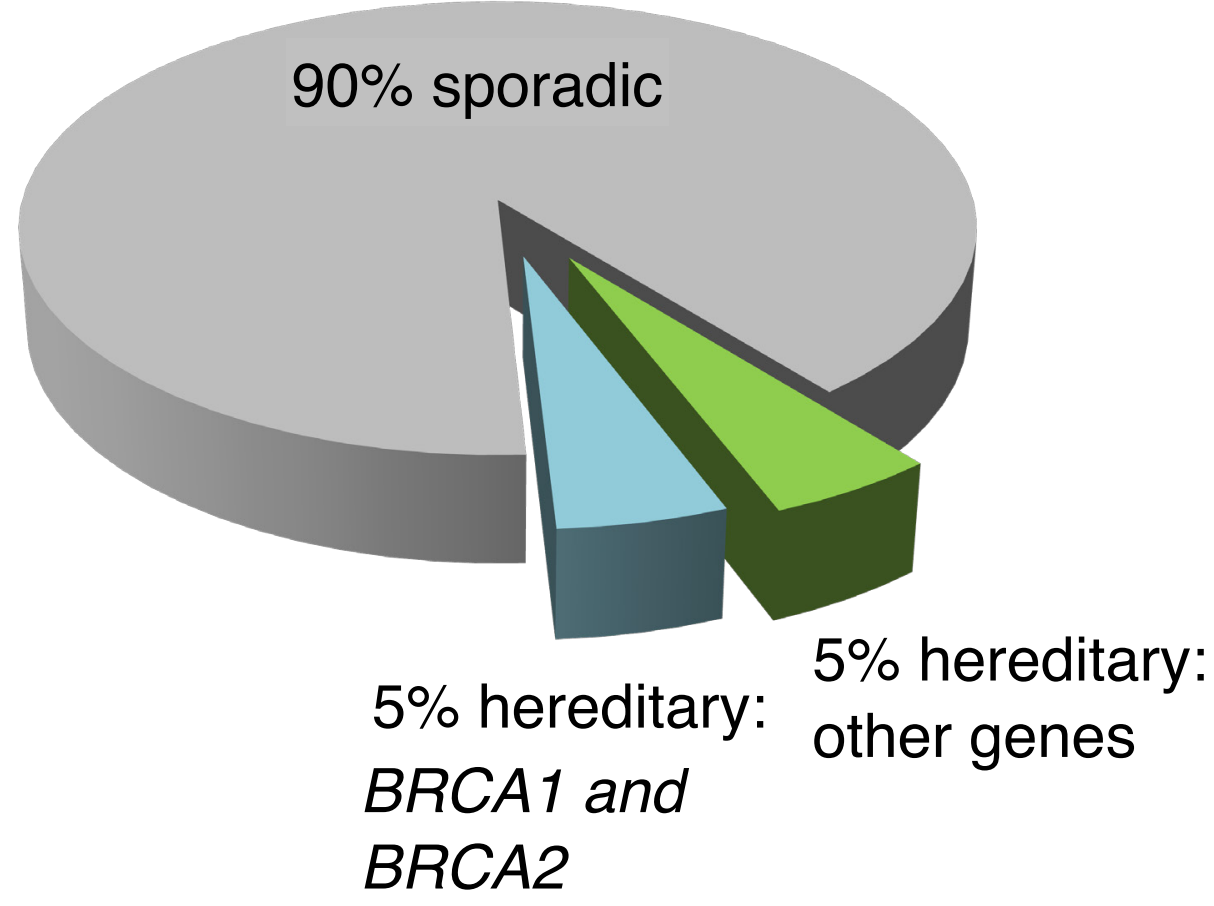




\section{Frequency of BRCA1 / 2 mutations in the population}

Rare!

- BRCA1:

1 out of 500 people affected

- BRCA2:

1 of 700 people affected
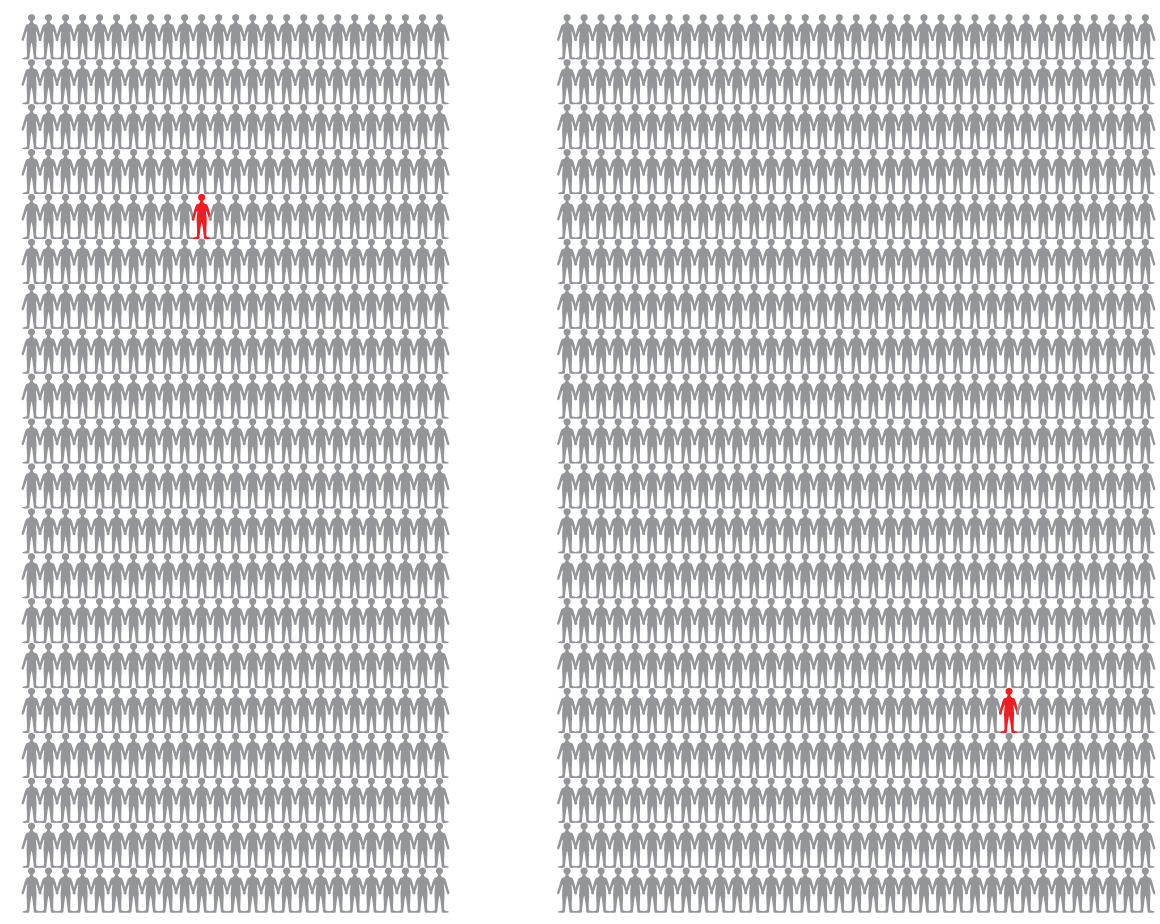


\section{Heredity}

- $50 \%$ chance of inheriting the altered gene $\rightarrow$ it is the same for every child

- Regardless of gender

- Non-carriers cannot pass on genetic change to children

$\rightarrow$ the altered gene cannot skip a generation!

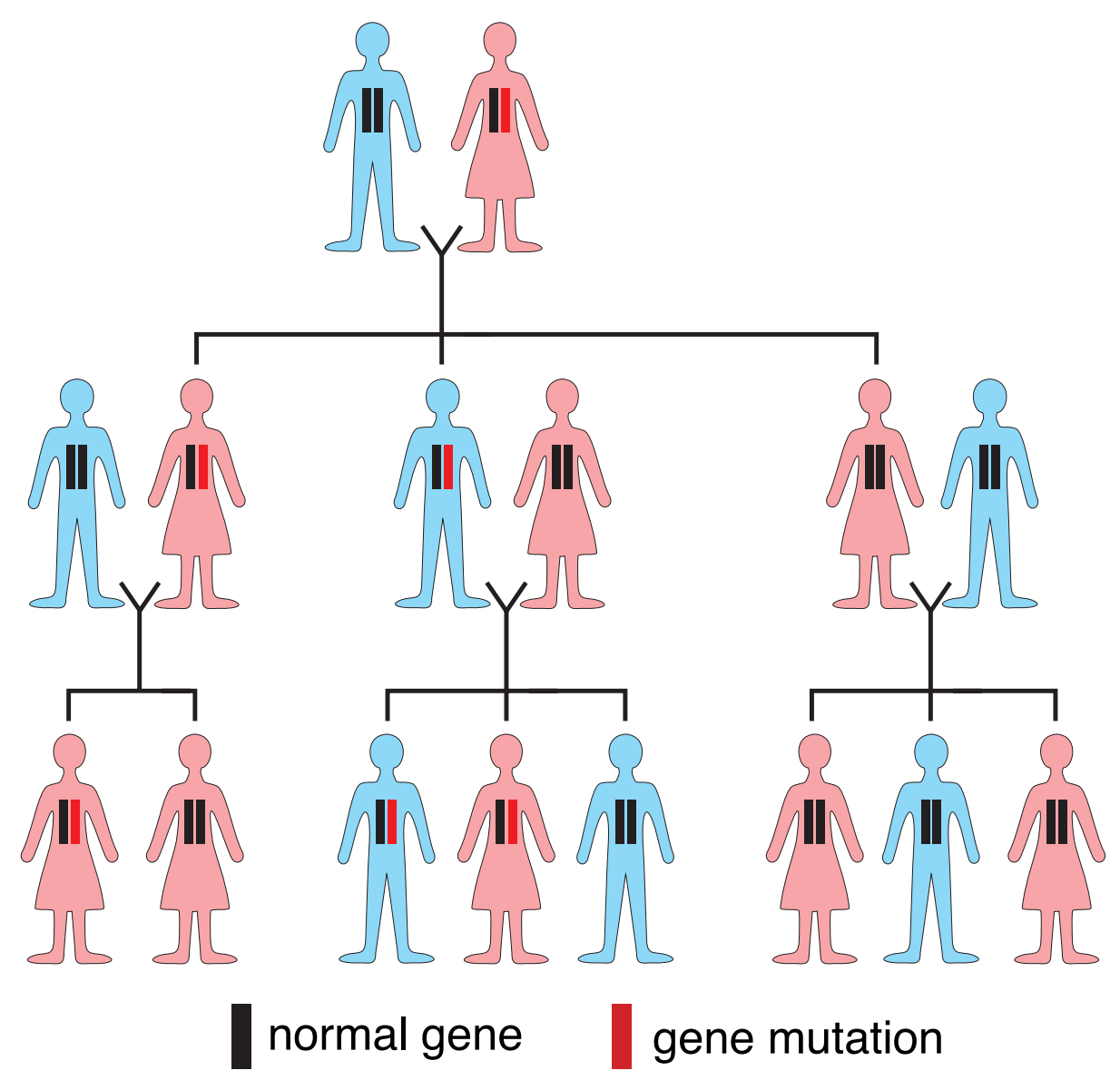




\section{Create your family tree}

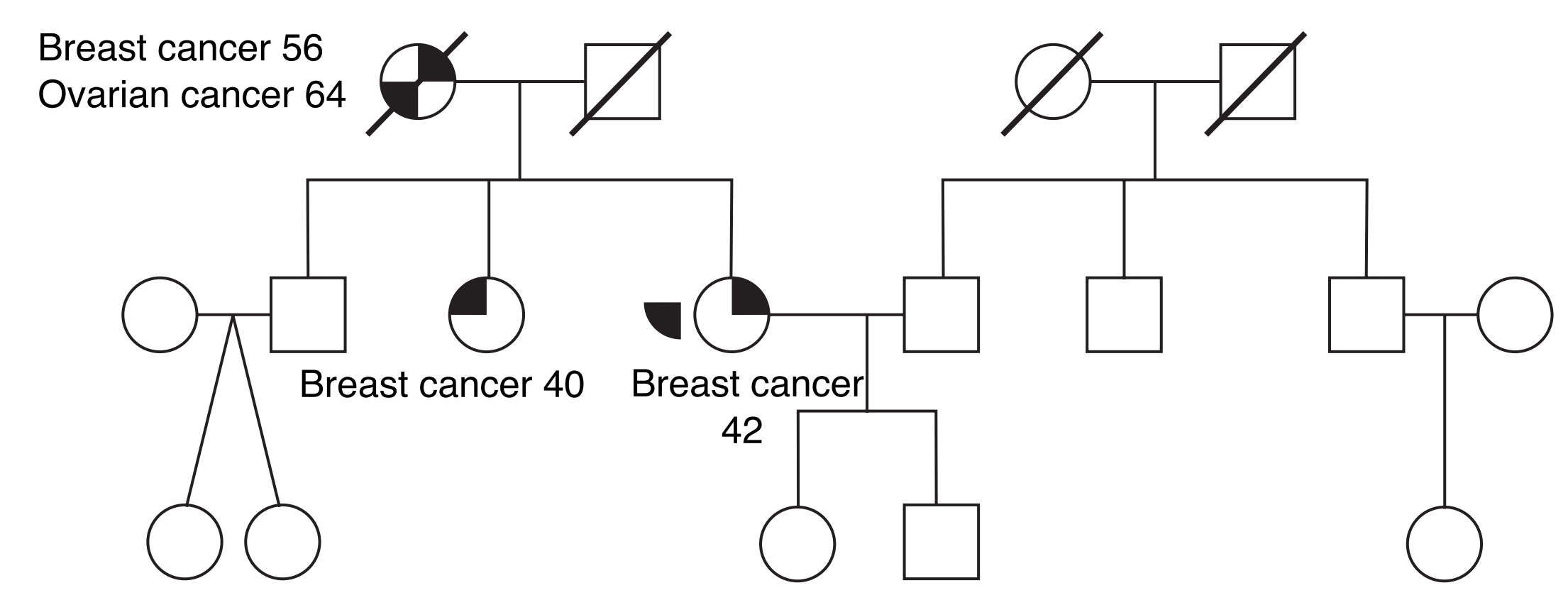

Explanation: Family tree of a sample family. The squares represents male; the circles represents female. Crossed out marks indicate that the person has died. A cancer is marked with a black corner. 


\section{Medical Indication}

- Maternal or paternal line: type and number of cancers, age of onset

- Presence of a familial high-risk constellation?

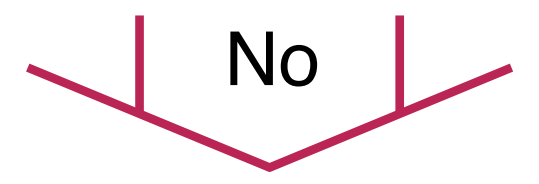

Not high risk;

No genetic testing necessary

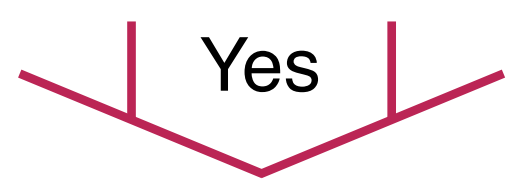

High risk;

Offer genetic testing 


\section{Possible results I}

(if no genetic mutation was found in the family)

\begin{tabular}{|l|l|}
\hline Results & Risk \\
\hline no mutation & unknown \\
\hline mutation & BRCA1: 85\% BC, 53\% OC \\
& BRCA2: 84\% BC, 27\% OC \\
\hline \multirow{2}{*}{ unclassified variant } & unknown \\
\hline
\end{tabular}




\section{Possible results II}

(if genetic mutation was found in the family)

\begin{tabular}{|l|l|}
\hline Results & Risk \\
\hline no mutation & General population \\
\hline mutation & BRCA1: 85\% BC, 53\% OC \\
& BRCA2: 84\% BC, 27\% OC \\
\hline \multirow{2}{*}{ unclassified variant } & unknown \\
\hline
\end{tabular}




\section{BRCA disease risk}

Disease risk

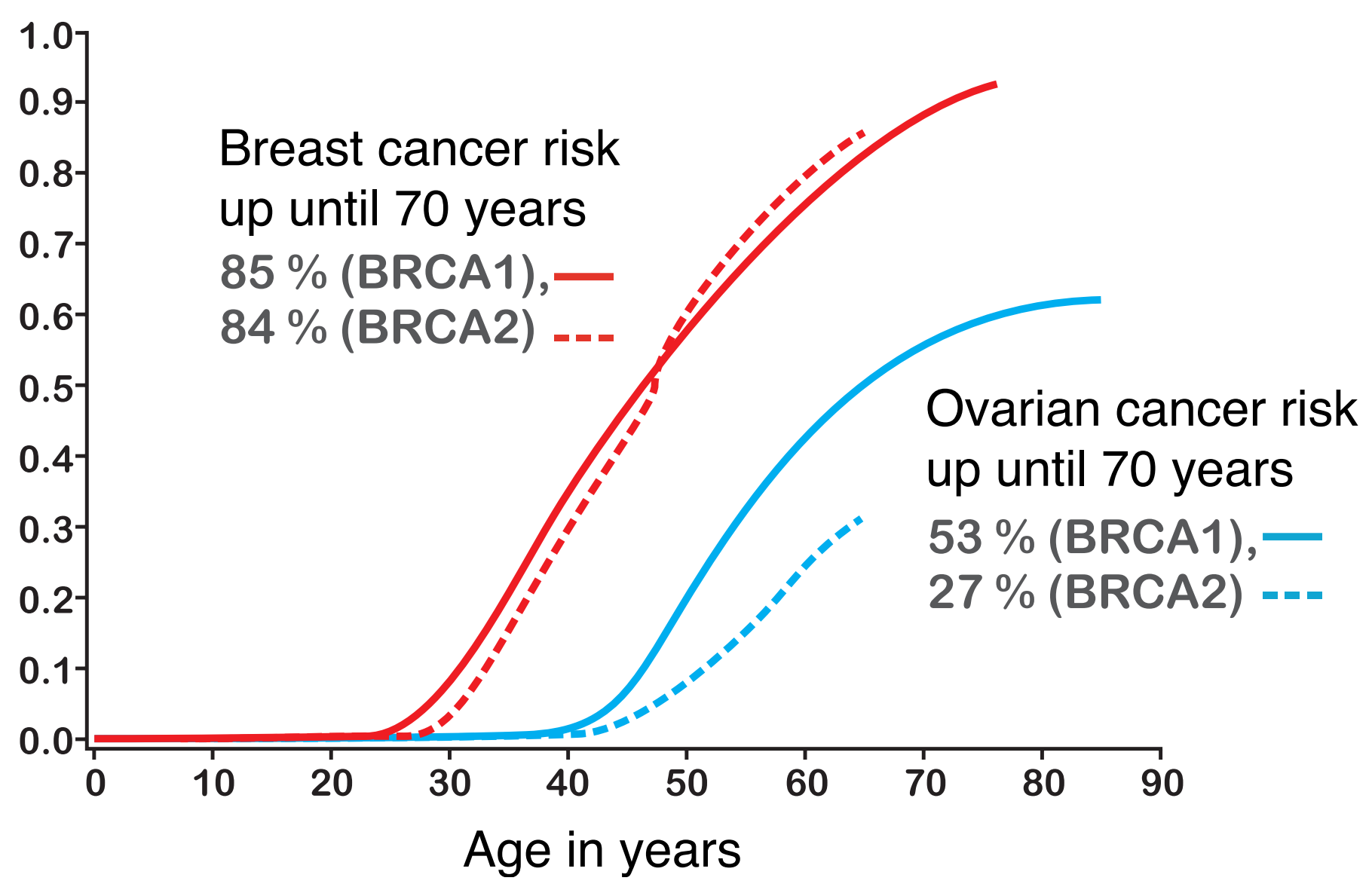




\section{Possible medical and psychosocial consequences}

\section{Early detection}

\section{Prevention}




\section{Screening program}

\begin{tabular}{|l|l|l|l|c|}
\hline Type of investigation & From 18y & From 25y & From 35y & $\begin{array}{c}\text { if } \\
\text { necessary }\end{array}$ \\
\hline Gynecological check & Once a year & & & \\
\hline Medical breast examination & Once a year & & & \\
\hline Breast ultrasound & & & & $x$ \\
\hline Mammography & & & Once a year & \\
\hline Breast MRI & & Once a year & & \\
\hline Vaginal ultrasound & & & Once a year & \\
\hline Tumor marker & & & Once a year & \\
\hline
\end{tabular}

Guideline of the Austrian Society for Senology, Austrian Society for Obgyn., Austrian Society for Surgery, Austrian Society for Radiology 


\section{Preventive Surgeries}

- Preventive removal of the breast tissue (prophylactic mastectomy)

- Preventive removal of ovaries and fallopian tubes (prophylactic ovariectomy, prophylactic bilateral salpingo-oophorectomy)

Risk of developing cancer, \%

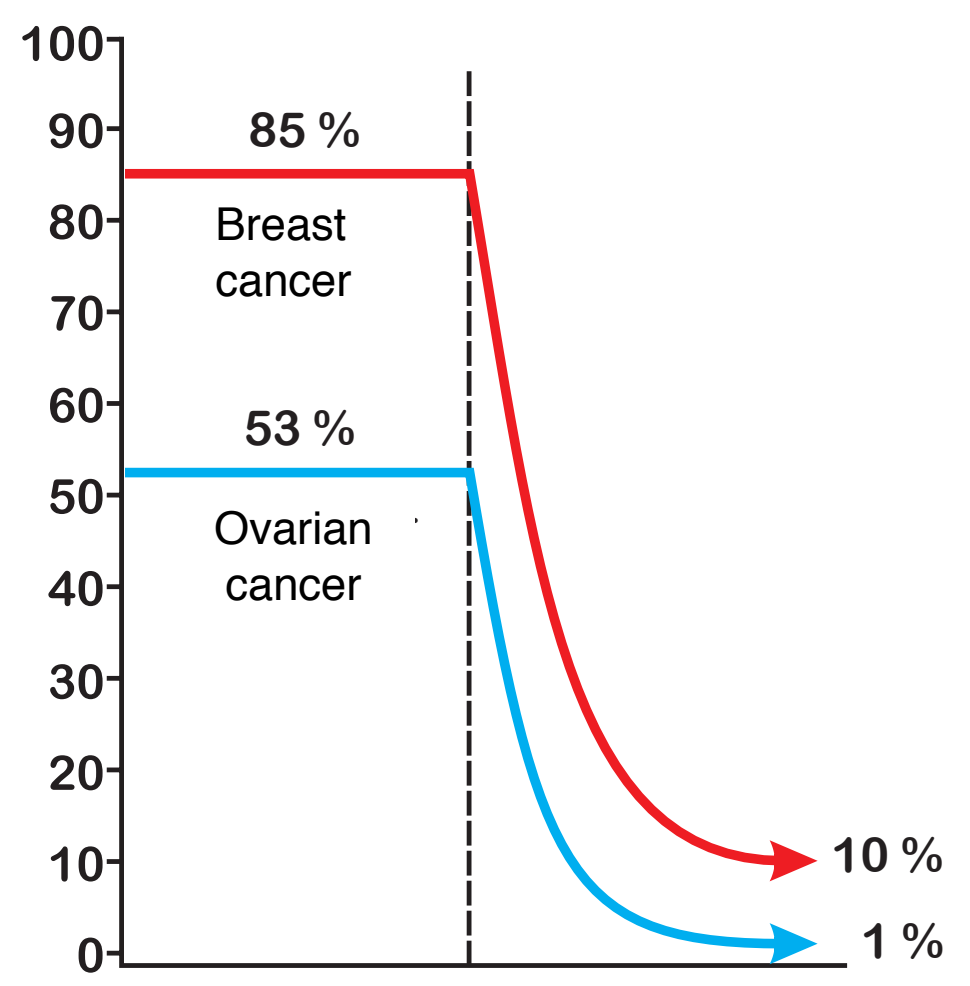




\section{Necessary considerations before an investigation:}

- How would you integrate an unfavorable result into your life?

-Which consequences would you presumably draw (e.g. early detection / preventive surgeries etc.)?

-Who would you tell about the gene mutation?

- How would you handle the information that your children might be affected by the hereditary disease risk? 


\section{Further process}

- Invitation to disclosure of test results

- Right to know i.e. to decide if you want to know the result or not

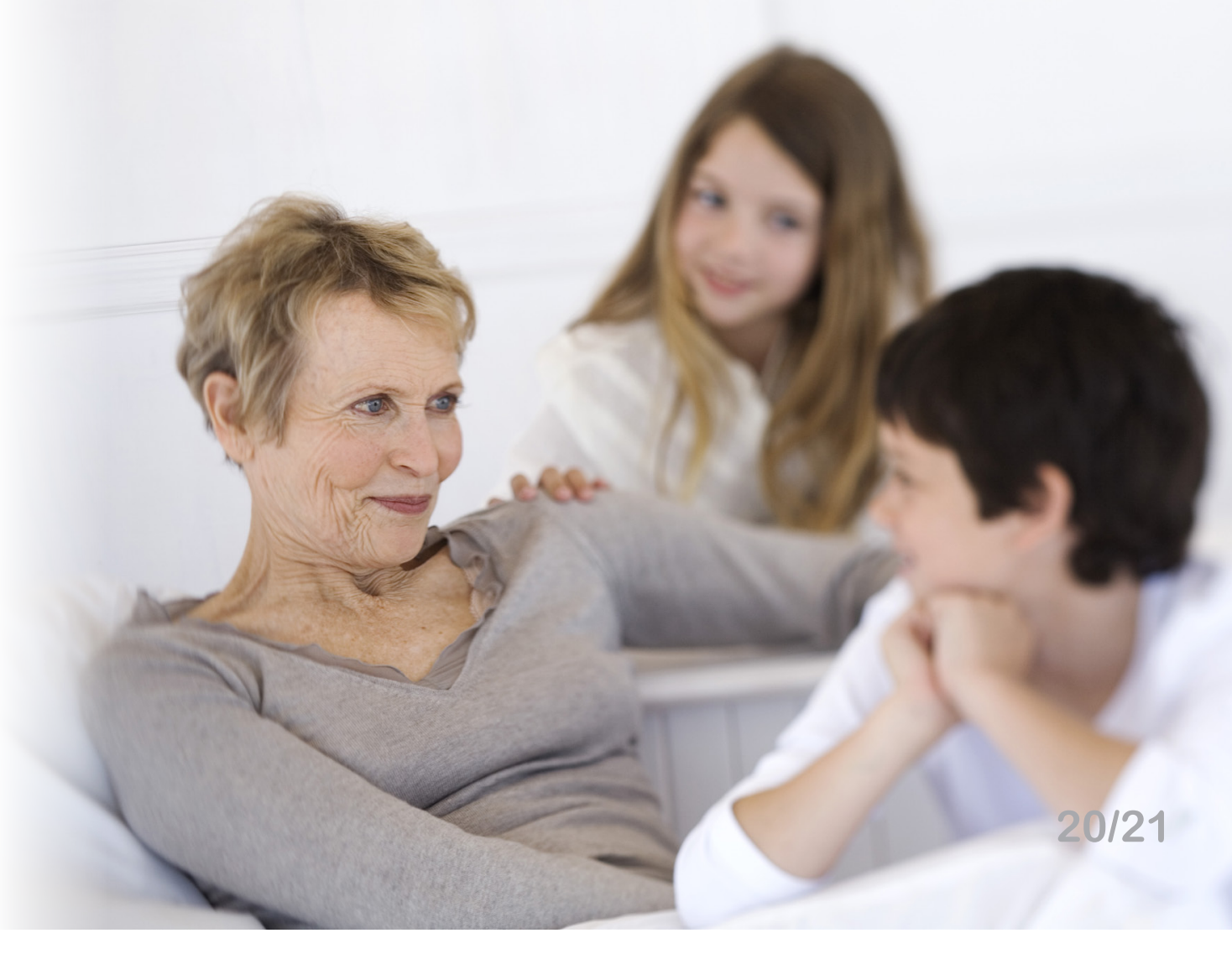


For more information:

\section{www.brustgenberatung.at}

